\title{
Original Epidemic Modeling for Plant Disease under Combined Effects of Wetness Duration and Temperature
}

\author{
Adil Soufi ${ }^{1}$ Mustapha Ait Rami ${ }^{2}$ \& Mustapha El Jarroudi ${ }^{3}$ \\ ${ }^{1-3}$ University Abdelmalek Essaadi, FST Tangier, Department of Mathematics, LMA, Morocco \\ ${ }^{2}$ ENSIT Engineering School Tangier, Laboratory Systems, Control \& Decision
}

Morocco

\begin{abstract}
This paper is concerned with the modeling and the fitting of an original epidemic model for plants disease. This model has the shape of a bump function which reflects the effect of the temperature and the wetness duration. Moreover, we provide a procedure that involves bounds constraints to fit the introduced model. In addition, our modelling accuracy and efficiency are evaluated for some reported studies in the literature. The simulation results are provided for the validation and in order to show the effectiveness of the proposed epidemic models for diverse plant infections reported in the literature.
\end{abstract}

Key Words: Plant disease, fungal infection, Epidemic Models, Fitting, Nonlinear Optimization.

\section{INTRODUCTION}

The conception of epidemiological models for plant diseases is one of the most important tool for predicting, controlling and estimating the infection incidence [1], [2]. This can be assessed by characterizing the influence of some environmental variables. In this study, we develop an model to predict infection incidence by pathogens as a function of the combined effects of temperature and wetness duration. The parameters of this model are estimated and adjusted according to the type of infection caused by various phytopathogenic agents. For this purpose, we introduce constraints on the model's location parameters and we minimize the sum of residuals based on the trust-region method. The proposed methodology presents a simple tool to use for the prediction and / or control of plant infection. In addition, the validation of our model is considered for different plant disease derived from several studies published in the literature [3], [4], [5]. We perform a comparison study and we show that the obtained goodness of fit results of the proposed model is more efficient than the other reported model.

The reminder of the paper is organized as follows. In Section 2, we introduce a plant infection model under the mixed effects of temperature and wetness. Section 3 provides a fitting procedure in order to estimate the involved model's parameters. In section 4, the proposed model is validated by using simulation results with comparison to various reported works in the literature. Finally, concluding remarks are presented in Section 5.

\section{MODELING PLANT DISEASES}

In this section, we introduce a model with mixed effects of some environmental on plant disease which characterize the relative infection response with regard to the effect of the temperature and the wetness duration. This model is defined as follows:

$$
y(t, w)=f(t, w)+e,(1)
$$

where

$$
f(t, w)=\left(1-\frac{1}{a_{1}\left(t-t_{I}\right)^{a_{2}+1}}\right)\left(1-\frac{1}{a_{3}\left(t_{C}-t\right)^{a_{4}+1}}\right)\left(1-\exp \left(-a_{5}\left(w-w_{I}\right)^{a_{6}}\right)\right)(2)
$$

and $y$ is the measure of the relative infection on a scale from 0 to $1, t$ is the temperature (in Celsius), $w$ is wetness duration (in hours) and $e$ is the model residual or perturbation error represented by an unknown random normal variable.

The biological meaning of the parameters of the disease model (1)-(2) is as follow

- $a_{1}, a_{2}, a_{3}, a_{4}$, and $a_{6}$ are the shape paramerters.

- $a_{5}$ is a speed parameter. 
- $\quad t_{I}, t_{C}$, and $w_{I}$ are the location parameters such that $t_{I}$ is the minimum temperature required for infection (in Celsius)

$$
t_{I}=\min (t \mid y \neq 0),(3)
$$

$t_{C}$ is the maximum temperature required for cure (in Celsius)

$$
t_{C}=\max (t \mid y \neq 0),(4)
$$

and $w_{I}$ is the minimum wetness duration for infection (in hours)

$$
w_{I}=\min (w \mid y \neq 0) .(5)
$$

Note that the proposed model (1),(2) possesses the shape of a bump function. In the sequel, we will fully characterize such function by estimating its parameters.

\section{Remark 1}

We stress out that by definition of the introduced model, the location parameters naturally satisfy the fact that for all $(t, w)$ we have:

$$
y\left(t_{I}, w\right)=y\left(t_{C}, w\right)=y\left(t, w_{I}\right)=0 .
$$

Proposition 1. The function $f$ take their values in the interval $[0,1]$ if and only if for all $i$ we have $a_{i}>0(6)$

Proof. The condition (6) implies the fact that the functions $f$ do not go to infinity at the boundary of the domain $\left[t_{I} t_{C}\right] \times w_{I}$. In addition, one can straightforwardly see that this function takes positive values only between 0 and 1 .

\section{MODEL ESTIMATION}

The estimation step in the modeling of plants disease is normally based on likelihood principle which under standing statistical assumptions. This principal is used to fit a given model to the observed data and it is equivalent to applying the least square method in the case when the measured values are independent and the residual model follows a normal distribution.

The fitting problem consists of estimating the parameters $a_{1}, a_{2}, a_{3}, a_{4}, a_{5}, a_{6}, t_{I}, t_{C}, w_{I}$ that are the optimal solution to the following nonlinear least square optimization (Sum of Squares Error (SSE) minimization)

$$
S S E:=\min _{a_{1}, a_{2}, a_{3}, a_{4}, a_{5}, a_{6}, t_{I}, t_{C}, w_{I}}\|y-\hat{y}\|^{2}(7)
$$

The objective criteria (7) is evaluated by using the sample data of measured temperature $T:=\left\{t_{1}, \ldots \ldots \ldots, t_{n}\right\}$ and the set of measured wetness duration $W:=\left\{w_{1}, \ldots \ldots \ldots, w_{n}\right\}$ with their corresponding observed relative infection $Y:=\left\{y_{1}, \ldots \ldots \ldots, y_{n}\right\}$. Then, in order to fit the model to the sample data $Y$ we simply use $\widehat{\boldsymbol{y}}=f(t, w)$ as defined by model (2)

The optimization problem (7) do not incorporate any information on the samples $\mathrm{T}$ and $\mathrm{W}$. In fact, to take into account the models conception, we introduce the following intrinsically bounds

$$
\left\{\begin{array}{c}
t_{C}^{-} \leq t_{C} \\
t_{I} \leq t_{I}^{+}, \quad(8) \\
w_{I} \leq w_{I}^{+} .
\end{array}\right.
$$

Such bounds endow the optimization problem (7) with a lower bound on $t_{C}$ and and an upper bounds respectively on $t_{I}$ and $w_{I}$.

In the following result, it is shown how to characterize the proposed bounds..

Proposition 2. In order to fit the data sets $(Y, T, W)$, the following bounds must hold

$$
\left\{\begin{aligned}
t_{C}^{-} & :=\max _{y_{i} \neq 0}\left(t_{i}\right), \\
t_{I}^{+} & :=\min _{y_{i} \neq 0}\left(t_{i}\right), \quad(9) \\
w_{I}^{+} & :=\min _{y_{i} \neq 0}\left(w_{i}\right) .
\end{aligned}\right.
$$


Proof. The argument line is straightforward from the construction of the bump function $f$.

Remark 2. In the above result one can see that the upper bound $t_{C}^{+}$and lowers bounds $t_{I}^{-}$and $w_{I}^{-}$are not characterized. In fact these additional bounds may be defined by setting them naturally to some empirical or trivial meteorological extremum values. For instance, set $w_{I}^{-}=0 \mathrm{~h}$ and more or less $t_{C}^{+}=40 \mathrm{C}^{\circ}, t_{I}^{-}=0 \mathrm{C}^{\circ}$. Consequently, the optimization problem (7) should be handled under the constraints

$$
\left\{\begin{array}{c}
t_{C}^{-} \leq t_{C} \leq t_{C}^{+} \\
t_{I}^{-} \leq t_{I} \leq t_{I}^{+},(10) \\
w_{I}^{-} \leq w_{I} \leq w_{I}^{+}
\end{array}\right.
$$

Now, the constrained nonlinear least square optimization problem under consideration for fitting the proposed models to the sample data $(Y, T, W)$ is adequately characterized by

$$
\min _{a_{1}, a_{2}, a_{3}, a_{4}, a_{5}, a_{6}, t_{I}, t_{C}, w_{I}}\|y-\hat{y}\|^{2}(11)
$$

Subject to

$$
\left\{\begin{array}{c}
\forall i, \quad a_{i}>0 \\
t_{C}^{-} \leq t_{C} \leq t_{c}^{+} \\
t_{I}^{-} \leq t_{I} \leq t_{I}^{+} \\
w_{I}^{-} \leq w_{I} \leq w_{I}^{+}
\end{array}\right.
$$

Such constrained optimization problem can be solved using nonlinear programming methods such as the classical Gauss-Newton with its many variants, Trust-Region or Interior Points method. We stress out that in general unlike the well-known commonly used linear least-squares method, the nonlinear least squares optimization problem is very hard to solve. In this case, it is not guaranteed to converge to the global minimum since we are dealing with a non-convex problem. In practice, these mentioned methods can perform well if the initial starting points are well guessed or can be close to the optimal solution.

\section{MODEL VALIDATION AND NUMERICAL RESULTS}

In part, we provide a comparison study with the most well known nonlinear models related to plant infection with various phytopathogenic agents under the combined effects of wetness duration and temperature.

The comparison models can be categorized into three classes as follows

- $\quad$ Beta model [5]:

$$
f(t, w)=a\left(t-t_{I}\right)^{b}\left(t_{C}-t\right)^{c} w^{d}(13)
$$

- Duthie's model [6]:

$$
f(t, w)=\frac{e(h+1) h^{\left((h-1)^{-1}-1\right)} \exp \left(g(h+1)^{-1}(t-f)\right)}{1+\exp (g(t-f))}\left(1-\exp \{-[b(w-c)]\}^{d}\right)
$$

- Polynomial model [7]: There is many kinds such that the $f(t, w)$ or the logit of $y$ is polynomial function $p(t, w) a s$

$$
p(t, w)=\log \left(\frac{y}{1-y}\right)=a_{0}+w\left(a_{1}+a_{2} t+a_{3} t^{2}+a_{4} t^{3}\right)(15)
$$

Note that $S S E$ index accuracy gives close estimates to the real observed disease score $y$. On the other hand, the goodness of the fit in the simulation study greatly depends on others statistical measures of performance such as $R^{2}$. This performance measure should be validated along with its adjusted value $R_{a}^{2}$ in order to indicate the strength of the linear relationship between the predicted and observed values as they become closer to the 1 that reflect a perfect fit.

To fit our model, we have used Trust Region method to solve the optimization problem (11). Matlab supports this method via the function fit. The chosen initial conditions $t_{I}^{0}, t_{C}^{0}$ and $w_{I}^{0}$ for the temperature and the wetness, are close to the proposed bounds on $t_{I}, t_{C}$ and $w_{C}$. For the others initial parameters $a_{i}$ we have chosen values between 0 and 1.

The simulation results in Tables [1,2]. Show that the proposed model is more performant than the other reported models in the literature [5], [4], [3]. It is clearly seen that our performance factors are better, we have significantly achieved a better fit, and we have outperform these reported models (13), (14), (15). 


\subsection{Parameters estimation}

In the following, we provide some simulation results for

- Medicinal Plant by Powdery Mildew

- Onion by Puccinia allii,

- Spinach White Rust

Table 1. Different infection models based on published studies relating fungal infection to temperature and wetness duration are given with $\mathbf{R}$-square $\boldsymbol{R}^{2}$, Adjusted $\mathbf{R}$-square $\boldsymbol{R}_{a}^{2}$, the sum of squares error $S S E$, Root mean squared error $R S S E$, the $\operatorname{symbol} *$ means that the values are not provided in the references.

\begin{tabular}{|c|c|c|c|c|c|c|c|}
\hline & & & & & & s of fit & \\
\hline Pathogen & Host & Moled & Ref & $R^{2}$ & $R_{a}^{2}$ & $S S E$ & $R S S E$ \\
\hline $\begin{array}{l}\text { Powdery } \\
\text { Mildew }\end{array}$ & $\begin{array}{l}\text { Picrorhiza } \\
\text { Kurrooa }\end{array}$ & $\begin{array}{l}\text { Beta } \\
\text { Regression } \\
\text { Model }\end{array}$ & $\begin{array}{l}{[8],[9],} \\
{[10],[5]}\end{array}$ & 0.81 & $*$ & $*$ & $*$ \\
\hline $\begin{array}{l}\text { Puccinia } \\
\text { allii }\end{array}$ & $\begin{array}{l}\text { Spring } \\
\text { Onion }\end{array}$ & $\begin{array}{l}\text { Duthie } \\
\text { Model }\end{array}$ & $\begin{array}{l}{[6],[11],} \\
{[4]}\end{array}$ & 0.9501 & $*$ & $*$ & $*$ \\
\hline $\begin{array}{l}\text { Spinach } \\
\text { White Rust }\end{array}$ & Spinach & $\begin{array}{l}\text { Polynomial } \\
\text { model }\end{array}$ & $\begin{array}{l}{[12],[13]} \\
{[7],[14],} \\
{[15]}\end{array}$ & 0.8917 & 0.8909 & $*$ & $*$ \\
\hline
\end{tabular}

Table 2. Parameters estimation for the model (1),(2) with their corresponding goodness of fit

\begin{tabular}{|c|c|c|c|c|c|c|c|c|c|c|c|c|c|c|c|}
\hline & & & \multicolumn{9}{|c|}{ Parameters } & \multicolumn{4}{|c|}{ Goodness of fit } \\
\hline Pathogen & Host & Ref & $a_{1}$ & $a_{2}$ & $a_{3}$ & $a_{4}$ & $a_{5}$ & $a_{6}$ & $t_{I}$ & $t_{C}$ & $w_{I}$ & $R^{2}$ & $R_{a}^{2}$ & SSE & $R S S E$ \\
\hline $\begin{array}{l}\text { Powdery } \\
\text { Mildew }\end{array}$ & $\begin{array}{l}\text { Picrorhiza } \\
\text { Kurrooa }\end{array}$ & [5] & $0.1 \mathrm{e}-3$ & 7.32 & $1.46 e-5$ & 1.67 & 0.039 & 1.15 & 30 & 37 & 1.354 & 0.972 & 0.957 & 0.079 & 0.0726 \\
\hline $\begin{array}{l}\text { Puccinia } \\
\text { allii }\end{array}$ & $\begin{array}{l}\text { Spring } \\
\text { Onion }\end{array}$ & [4] & 0.147 & 2.42 & $0.24 \mathrm{e}-3$ & 6.15 & 1.56 & 0.91 & 0.79 & 27.7 & 0.966 & 0.955 & 0.931 & 0.171 & 0.1071 \\
\hline $\begin{array}{l}\text { Spinach } \\
\text { White } \\
\text { Rust }\end{array}$ & Spinach & [15] & $0.4 \mathrm{e}-2$ & 3.9 & 0.0034 & 2.58 & 0.005 & 1.55 & 5 & 30. & $9.4 \mathrm{e}-6$ & 0.9 & 0.891 & 0.750 & 0.0918 \\
\hline
\end{tabular}

\subsection{Simulation figures}

In the sequel, some figures are depicted to illustrate our simulation results. 

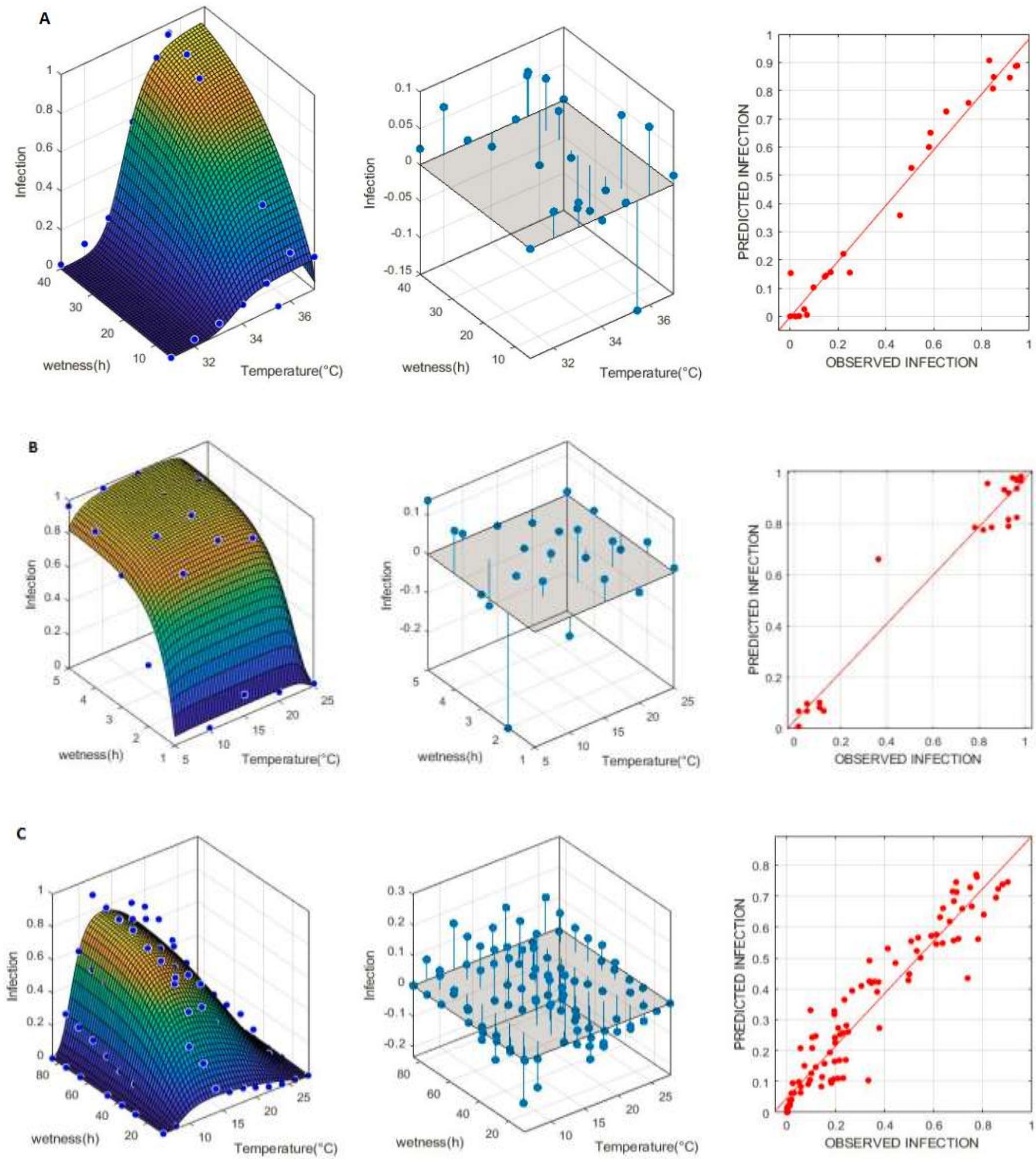

Figure 1 : Observed and predicted values of the relative incidence of infection using model (1) with the residuals versus the fitted values. A: Medicinal Plant by Powdery Mildew, B:Onion by Puccinia allii, C: Spinach White Rust

\section{CONCLUSION}

The model and the method presented in this paper are original. We have provided a suitable epidemic modeling by using simple techniques for plant disease analysis. This can be useful for disease prediction and control. Moreover, the comparison study have shown the primacy of the proposed epidemic model that outperforms the other reported models. 


\section{REFERENCES}

1. R.A.Krause, and B.L.Massie, "Predictive Systems: Modern Approaches to Disease Control," Annual Review of Phytopathology, vol. 13, pp. 31-47, 1975.

2. M.L.Delignette-Muller, "Principles of Predictive Modeling. In: Toldrá F. (eds) Safety of Meat and Processed Meat," Microbiology and Food Safety. Springer, pp. 535-558, 2009.

3. G.G.Grove, L.V.Madden,M.A.Ellis,A.F.Schmitthenner, "Influence of temperature and wetness duration on infection of immature strawberry fruit by Phytophthora cactorum," The American Phytopathological Society, vol. 75, no. 2, 1985.

4. H.Furuya,H.Takanashi,S.Fuji,Y.Nagi and H,Naito, "Modeling infection of spring onion by Puccinia allii in response to temperature and leaf wetness," Phytopathology, vol. 99, no. 8, 2009.

5. R.V.D.Sharma,D.Shivling, D.Kumar,A.K.Sharma, " A Beta Regression Model for Himalayan Medicinal Plant Disease Prediction," Indian Journal of Science and Technology, vol. 7(6), p. 776-780 , 2014.

6. J. A.Duthie, "Models of the response of foliar parasites to the," Phytopathology, vol. 87, pp. 1088-1095, 1997.

7. K.J.Evans, W.E.Nyquist, and R.X.Latin, "A model base on temperature and leaf wetness duration for establishment of Alternaria leaf blight of muskmelon," Phytopathology, vol. 82, pp. 890-895, 1992.

8. S. Analytis, "On the relation between biological development and temperature of some plant pathogenic fungi," Phytopathol. Z, vol. 90, pp. 64-76, 1977.

9. L.L.May De Mio, and L. Amorin, " Influence of temperature and leaf wetness duration on the monocyclic components of the poplar rust," Summa Phytopathol, vol. 28, pp. 33-39, 2002.

10. O.Erincick, L.V.Madden, D.C.Ferree, and M.A.Ellis, "Temperature and wetness-duration requirements for grape leaf and cane infection by Phomopsis viticola," Plant Diseas, vol. 87, pp. 832-840, 2003.

11. L.J.Wu, J.P.Damicon, L.A.Duthie, and H.A.Melouk, " Effects of temperature and wetness duration on infection of peanut cultivars by Cercospora arachidicola," Phytopathology, vol. 89, pp. 653-659, 1999.

12. N.Lalancette, M.A.Ellis, and L.V.Madden, " Development of an Infection Efficiency Model for Plasmopara viticola on American Grape Based on Temperature and Duration of Leaf Wetness," The American Phytopathological, vol. 78, no. 6, 1988.

13. W.Schuh, "Influence of temperature and leaf wetness period on conidial germination in vitro and infection of Cercospora kikuchii on soybean," Phytopathology, vol. 81, pp. 1315-1318, 1991.

14. L.H.Jacome, and W.Schuh, "Effects of leaf wetness duration and temperature on development of black Sigatoka disease on banana infected by Mycosphaerella fijiensis var. difformis," Phytopathology, vol. 82, pp. 515-520, 1992.

15. M. J. Sullivan, J.P.Damicone, and M.E.Payton, "The Effects of Temperature and Wetness Period on the Development of Spinach White Rust," The American Phytopathological Society, Plant Disease, vol. 86, no. 7, 2002. 